\title{
Response to national policy imperatives for nursing education: a Western Cape case study
}

\author{
FM Daniels, MPH \\ Senior Lecturer, School of Nursing, University of the Western Cape
}

\section{Kev words}

Transformation, restructuring, nursing education, common teaching platform, undergraduate nursing, higher education.

\begin{abstract}
Curationis 33 (1): 42-48
Since South Africa became a democratic country in 1994, the higher education sector has been faced with the challenge of transformation and restructuring. The Minister of Education in the Education White Paper 3 stated that "the higher education system must be transformed to redress the past inequities, to serve a new social order, to meet pressing national needs and to respond to realities and opportunities" (Department of Education, 1997:2). Higher education institutions were faced with the realities of impending mergers and collaborations across programmes and between universities and technikons. The Council on Higher Education (CHE) submitted a report to the Minister of Education in February 2002 which proposed the establishment of new institutional and organizational forms within regions (Department of Education, 2002: 7-8). The Minister announced changes in higher education based on his assessment of the proposals submitted by the CHE which resulted in the reduction of the number of higher education institutions from 36 to 21 (Department of Education, 2002: 11-20).

There were specific implications for nursing education in the Western Cape. In December 2002 the Minister of Education, Kader Asmal announced that with effect from 2005, the University of the Western Cape (UWC) and a new institution, the Cape Peninsula University of Technology (CPUT) would be the only enrolling institutions for undergraduate nursing education in the Western Cape. The Cape Higher Education Consortium (CHEC) instead proposed the establishment of a common teaching platform for nursing education in the region to meet the objectives of national and provincial government and to make optimal use of the combined strengths of the three universities and the technikon. This proposal was accepted by the minister and the common teaching platform, a unique form of collaboration, was established in 2005.
\end{abstract}

\section{Correspondence address}

Mrs F.M Daniels

School of Nursing

University of the Western Cape

Private Bag X17

Bellville 7535

Tel: (021) $959-2443$

Fax:(021) 959-1488

Email: fdaniels@uwc.ac.za 


\section{Introduction and background}

Policy articulation and policy contestation regarding higher education was highly debated during South Africa's transition from apartheid to democracy. Thereafter, during the post apartheid period, there was evidence of extensive policy development and implementation affecting higher education. Rigorous efforts were made by the newly elected political party, the African $\mathrm{Na}$ tional Congress, to unify and streamline the education system. Redress of inequities was high on the agenda of the government through the Department of Education. The highly contentious higher education policies of the apartheid government were abandoned and new policies to ensure that the higher education system became more functional, relevant and responsive to societal needs were adopted.

Consequently, since the beginning of the $21^{\text {st }}$ century, the higher education sector throughout South Africa has been faced with the challenge of transformation and restructuring. Institutions were faced with the realities of impending mergers and collaborations across institutions and programmes, a phenomenon not unique to South Africa but also to the rest of the world.

Jansen (2003:29-35) describes these mergers within the transitional context as a product of the complex interplay between governmental macro politics and institutional micro politics. Jansen observed that all mergers in higher education proceeded despite intense political resistance from constituencies, compared to other state-mandated cases where institutions decided not to merge, merged and subsequently delinked or merged in unforeseen ways. The nursing education case study in the Western Cape highlighted in this article is one example of variation from the type of collaborations originally planned for higher education institutions.

The purpose of this article is to contextualise and describe how nursing education in the Western Cape responded, in terms of its application, to the higher education policies of transformation and restructuring, against the backdrop of the impact of apartheid on the education system of South
Africa. The article also explores the concepts of collaboration and mergers and highlights the international and national experiences of these approaches in higher education.

\section{South African education system during the period of apartheid}

To contextualize and understand the current, changing educational system in South Africa in general and the higher education system in particular, it is essential to study the past sociopolitical and economic climate of this country and the specific impact it had on it's citizens.

The political ethos of South Africa has been shaped by racism and segregation. The official policy of apartheid began when the South African National Party won the 1948 General Election (Brown, 2004:169). According to Brown, the political regime which followed was based on "apartness" which in Afrikaans means "apartheid", a separation of the people of South A frica into racial classifications of White, Black, Coloured or Indian. Numerous laws which supported the dominance of White over non-white people were passed, and these shaped the lives of South African citizens.

This meant that Whites and non-whites (Coloureds, Blacks and Indians) lived separately, married only into their own racial groups, were schooled separately, and had unequal and separate access to amenities. Consequently the development of non-white people was restricted, leaving the population of South Africa divided into the white "haves", and non-white "have-nots."

By denying basic human rights to some citizens, apartheid laws and homeland policies created a deeply entrenched system of racial discrimination and inequity in South Africa (Brown, 2004:171). Furthermore, denying access to education at all levels contributed to poverty, crime and violence and inhibited societal development in general. Lack of access to amenities meant lack of resources to uplift the educational experience of non-whites and thus the best paying jobs were at the feet of educated whites. In this way the cycle of poverty, inequity, polarities, fragmentation, discrimination and sepa- rateness was perpetuated.

Higher education post apartheid

In 1994, South Africa was declared a democratic country under the governance of the African National Congress. However, after more than a decade of democracy, South Africa is still plagued with severe socio-political and economic challenges, including challenges in the education sector.

Jansen $(2003: 29-31)$ puts forward the following transitional conditions and challenges faced by higher education at the end of the apartheid period:

- The higher education system was divided by racial inequities where institutions carried with them reminiscent of their separate histories: black and white.

- Black universities experienced student and staff conflicts and violence related to financial difficulties and the style of management of the institution.

- Institutions experienced a dramatic decline in student enrolments which was devastating for struggling universities. The few good black students went to urban white universities leaving the black universities having to accept under-prepared students

- Black universities were situated in impoverished rural areas with little economic infrastructure for local development and the expansion of the institution.

In response to such challenges, the National Commission on Higher Education (NCHE) conducted an investigation during 1995-1996 and proposed that "non statutory regional structures should be established to consult a region on its planning needs, possible mergers, rationalisation, programme distribution, sharing of resources and the development of higher education institutions" (NCHE, 2006). This was advocated by the South African government.

The Education White Paper 3: A Programme for the Transformation of Higher Education, released in July 1997 , in support of the NCHE report, recognises that South Africa's transition from apartheid to democracy requires a review of practices, institutions and values in terms of their fitness for the new 
democratic era since higher education is pivotal to the socio-cultural and economic development of society (Department of Education, 1997:2). The Minister of Education, in the Education White Paper 3 stated that the transformation of the higher education system (in South Africa) is not negotiable. He further stated that "the higher education system must be transformed to redress the past inequities, to serve a new social order, to meet pressing national needs and to respond to realities and opportunities" (Department of Education, 1997:2).

The National Plan for Higher Education (Department of Education, 2001), provided a framework for the implementation of the vision for higher education and the programme for transformation nationally. It was envisaged that transformation of the higher education system would mean: increased and broadened participation to overcome fragmentation, inequality and inefficiency; that higher education institutions must respond to societal needs and interests to enable participation in a competitive global context and; the development of co-operation between higher education and the state, civil society and stakeholders and the development of partnerships in governance (Department of Education, 1997:4$5)$.

One of the processes initiated by the ministry to achieve the goals of the National Plan for Higher Education was the establishment of the National Working Group (NWG) in March 2001. The NWG in collaboration with the Council on Higher Education (CHE), established in May 1998 through the Higher Education Act 101 of 1997, was appointed to investigate and advise the minister on appropriate options for the provision of higher education on a regional basis through establishing new institutional and organizational forms. The CHE was also tasked to investigate the feasibility of reducing the number of higher education institutions (CHE Annual Report, 1999/2000:12; Department of Education, 2002:7-8). The CHE submitted a report highlighting their proposals to the Minister of Education in February 2002. The Minister then announced the proposed changes based on the proposals submitted by the CHE which resulted in the reduction of the number higher education institutions from 36 to 21 (Department of Education, 2002:11-20). This announcement had specific implications for nursing education in the Western Cape.

\section{Transformation and}

restructuring of higher education through collaborations and

\section{mergers}

\section{Clarifying the concepts of collaboration and mergers}

Collaborations and mergers are not synonymous concepts. This section attempts to provide clarity in differentiating between the two concepts, and uses concrete examples from the policy decisions around the transformation and restructuring of the higher education system in South Africa to illustrate their application.

\section{Collaboration in higher education}

Collaboration implies a partnership or team work. This refers to institutions in a region that remain separate, but combine their expertise, efforts and infrastructural resources in the delivery of higher education programmes. The Minister of Education envisaged that collaboration in programme development, delivery and rationalisation would result in enhancing diversity in the provision of higher education programmes and reducing costs within the region. Furthermore, the collaborative use of academic expertise and human resources would strengthen programmes. Infrastructural collaborations between higher education institutions would contribute to the efficient use of facilities and resources for teaching, learning and research. Such transformation would ensure the development of a coherent system and contribute to addressing the social, educational, economic and political challenges within the higher education system (Department of Education, 2001: 68-71).

The implementation of collaboration is however understood to be highly complex. One or more institutions involved may feel that the collaboration will lead to a loss for their particular institution, which may lead to resistance.
Collaborative approaches include:

(i) Voluntary collaboration: where institutions are highly motivated to collaborate with each other. It is usually in academic programme areas and can be managed at faculty level with little to no regional governance resources

(ii) Institutionally-driven collaboration: where senior leadership of institutions are keen to collaborate, with low levels of interest from other levels of staff. Collaboration opportunities are identified at institutional planning level or through the regional planning review and would require full regional governance resources

(iii) Externally-driven collaboration: where there is low interest in collaboration amongst institutions concerned. Collaboration is identified by the Ministry as an opportunity to rationalise (Leatt, Rezelman, Blyth \& Symes, 2002:4-6).

\section{Mergers in higher education}

Mergers refer to joining, amalgamations and combining of institutions in an attempt to reduce the number of geographical sites. The purpose of merging historically black with historically white universities for example, is viewed as an attempt to address racial fragmentation and inequities within the higher education system. Mergers are also viewed as a mechanism for streamlining programme offerings and costs to ensure sustainability of the higher education system. It also attempts to ensure efficiency in the governance, management and administration systems within higher education (Department of Education, 2001:75). Jansen (2003:29-35) argues that the government's motivation for instituting mergers has little to do with issues of equity. Rather, it had more to do with the reduction of costs.

Mfusi (2004:98-99) postulates that in the process of merging, the curriculum is treated as secondary to the financial and organizational changes which occur due to the mergers. The author furthermore reported that mergers are not done to resolve problems with the curriculum which are at the heart of the teaching and learning process. 


\section{International experiences of collaborations and mergers}

Several collaborative efforts in nursing education at international institutions are documented. It is evident from literature that there are different models and approaches for collaboration depending on the underlying factors that elicit the need for collaboration. Collaboration efforts internationally are referred to as "consortia" or "partnerships" or "collaborative nursing programs".

Partnerships in nursing programs abroad are not limited to collaboration between universities only, but exist between colleges as well, and extend to include collaboration between universities and colleges and between education institutions and health care services.

The nature of collaborations internationally includes programmes where students:

- Complete the first two years at either a partner college or university while all students must complete the last two years at the university

- Complete the entire degree programme at any partner institution while the degree is conferred by the partner university only

- Complete their nursing degree at any partner institution but the non- nursing courses at a prescribed academic department

- Complete common courses of a masters program at any partner institution and register for a non-duplicated nursing specialization at the offering institution (Lund, Tate \& HydeRobertson, 1998:13-16; Molzahn \& Purkis, 2004:42-43; Oregon Consortium for Nursing Education (OCNE), 2007:6-7).

Molzahn \& Purkis (2004:41-55) alluded to the fact that collaboration in nursing programmes in Canada have occurred for the past 20 years as a strategy to increase access to baccalaureate level nursing. When this became the minimum requirement for entrance to the nursing profession in 2005 , diploma programmes were discontinued.

More recently (OCNE, 2007:1) de- scribed a partnership in Portland between community colleges and public and private university schools that was established in response to the critical nursing shortage. The OCNE agreement signed by partner schools in May 2006 is characterized by:

- The guiding principle that each individual school retains full responsibility and accountability for the nursing program

- A collaborative process for consensus about a curriculum and agreements that are needed to support the shared curriculum

- Improved utilization of clinical facilities and faculty expertise in Oregon through collaborative planning for clinical experiences, joint or adjunct faculty appointments and shared expertise in instructional design

- $\quad$ Shared agreement for student support services, academic standards and purchasing power to equip strategically located simulation laboratories (OCNE, 2007:1-2).

\section{National and local experience of collaborations and mergers}

Mergers or incorporations in the general higher education system were proposed within several provinces of South Africa by the Ministry of Education in 2002. These included amongst other, the incorporation of the South African College of Teacher Education (SACTE) into the University of South Africa (UNISA); the Johannesburg College of Education (JCE) into the University of the Witwatersrand (Wits); Giyani College of Education (GCE) into the University of Venda for Science and Technology (UNIVEN); the merger of ML Sultan Tecknikon ((MLST) and the Technikon Natal (TN) to form the Durban Institute of Technology (DIT) now the Durban University of Technology (DUT); and the Faculties of Veterinary Science (FOVS) of the Medical University of South Africa (MEDUNSA) and the University of Pretoria (UP) (Jansen, 2003:27).

The implications of mergers resulted in changes in the offering of nursing education within the provinces where for example the University of Fort Hare was retained as a separate institution but incorporated the East London campus of the Rhodes University and the Health Science Faculty of the University of the Transkei (Department of Education, 2002:11-18).

Higher education institutions in the Western Cape, including nursing education, were not spared the challenge of moving into mergers and collaborations. Nursing education at higher education level was identified as a priority for academic program collaboration (Department of Education, 2001:70-74). It was identified that restructuring in the Western Cape would be done through programme and infrastructural co-operation, rationalization of programmes offered by the five higher education institutions in the region (three universities and two technikons) and collaboration in infrastructural development. (Department of Education, 2001: 70-74).

The impact on nursing education came through the announcement of the Minister of Education, Kader Asmal in December 2002, that with effect from 2005 the University of the Western Cape (UWC) and the new institution, Cape Peninsula University of Technology (CPUT), resulting from the merger of the Cape and Peninsula Technikons would be the only enrolling institutions for undergraduate nursing education in the Western Cape. This meant that both the University of Cape Town (UCT) and Stellenbosch (US) would no longer enrol undergraduate nurses but would rather contribute their strengths in a collaborative way with UWC, in order to train nurses in the region (Department of Education, 2002:17).

\section{Rationale for Collaboration in the Western Cape}

Leatt et al (2002:4-6) suggested that there would be substantial benefits to higher education in the Western Cape and additional benefits to institutions located geographically close to each other, if they co-operated in a structured and intentional way.

Two broad reasons for regional collaboration are provided:

(i) The first refers to transformation on both a global and a national level. "Globalisation of knowledge and the changing knowledge economy and the 
creation of a global higher education market", has required that higher education institutions transform and become more competitive, remain useful and viable (Leatt et al, 2002: 4-6). Higher education institutions are challenged to compete with foreign international institutions in attracting students from all over the world or extending their programmes, through the use of technology, into foreign markets as well as preparing students for the global market. This should expand far beyond what is currently the case in South Africa, where foreign students studying at some universities in South Africa are mainly from foreign countries within Africa.

Despite the fact that the vision for nursing education programmes in South Africa is firstly to prepare graduates to serve the needs of the local and national communities, it is a fact that South African nurse graduates are being attracted to foreign countries through their lucrative benefits. Nursing programmes must therefore be made more attractive and must respond to the changing social needs and meet quality standards in order to keep nurses in South Africa (Leatt et al, 2002: 4-6). However, given the exodus of qualified nurses out of South Africa in search of greener pastures in their professional lives, higher education institutions and nursing education in particular should prepare the graduate to compete in the global market.

The shortfall of approximately one thousand nurses, of all categories in the Western Cape public sector, makes nurse training a priority in the region. The Provincial Government of the Western Cape (PGWC) has therefore identified the provision of bursaries to nurses in training as an important human resource strategy to remedy the deficit of nurses in the province.

Leatt et al (2002: 4-6) furthermore elaborates on the argument noted in the Education White Paper 3, that the transition from apartheid to democracy requires a review of practices, institutions and values in terms of their fitness for the new democratic era. Higher education must address the need for a restructured national system which reflects the ratio of the general population in terms of demography in its staff and students. It must further address the regional needs for economic and social development, and the need for a fully articulated education system which serves the needs of learners.

ii) The second reason for collaboration is to increase operational efficiency and the effectiveness of institutions. This includes the merger of routine administrative and service functions that will result in lower costs and the pooling of resources for example libraries and information and communication technology (Leatt et al 2002:4-6).

It was assumed that there was duplication of effort and resources in nursing programmes offered in the Western Cape as well as in other provinces resulting in inefficiency. According to Hay, Fourie \& Hay (2001:100-108) the Education Minister at the time alluded to the fact that all institutions were trying to do the same thing. According to Leatt \& Pretorius (2004:7) higher education institutions "behave like autonomous, self-sufficient, and highly competitive silos" which they argue are the remnants of apartheid. Instituting common teaching platforms is not only an attempt at overcoming the "silo-effect" but a response to the globalization of knowledge in the world of scholarship (Leatt \& Pretorius, 2004:7)

Hay, Fourie \& Hay (2001:102) cautioned that institutional collaborations and mergers are a thorny issue which create uncertainties amongst staff because of possible downsizing and the need for staff to make paradigm shifts due to institutional change. They further argue that mergers may create a clash of institutional cultures in terms of their educational philosophies and institutional priorities. Where there are quality differences, one partner might fear that their reputation might be tarnished.

\section{Common teaching platform for undergraduate nursing in the Western Cape: Case study}

As noted earlier, the Minister of Education Kader Asmal announced in December 2002 that the University of the Western Cape (UWC) and the new institution, Cape Peninsula University of Technology (CPUT), resulting from the merger of the Cape and Peninsula Technikons, would be the only enrolling institutions for undergraduate nursing education in the Western Cape
(Department of Education, 2002:17).

This ruling meant that the region would lose the contributions of both the University of Cape Town and the University of Stellenbosch since they would no longer enrol undergraduate nursing students. The Cape Higher Education Consortium (CHEC) however believed that it was possible to develop a common teaching platform for nursing education in the region that would meet the objectives of national and provincial government whilst making optimal use of the combined strengths of the three universities and technikon. It was envisaged that the new nursing education model should be cost-effective, meet current and future needs for nurses and embrace and embody best practice for nurses with a curriculum that is flexible and which reflects modern teaching and learning principles (CHEC, 2006: 9-10).

A proposal of the model for the common teaching platform was submitted to the Minister of Education in October 2003. The Minister gave CHEC inprinciple approval of the proposal. An integrated planning framework and memorandum of understanding (MOU) for a common teaching platform for undergraduate nursing education in the Western Cape was drawn up by a project team. This document was presented to the CHEC Board of Directors to be approved and adopted, and tabled for approval by the Senates and Councils of each participating institution. This process however was only completed after several recommended revisions served at constituted meetings and passed through all the aforementioned committees (CHEC, 2006:10)

Planning for the establishment of the common teaching platform required representation from all participating institutions. Several working groups were formed after the proposal for the collaboration was accepted. These working groups were tasked with preparing the curriculum, planning for the clinical component of the programme and for resources, amongst other.

The MOU is recognised as the binding mechanism for collaboration of CHEC member institutions who, by virtue of their autonomy otherwise would not be 
obliged to make critical decisions that "limits their autonomy", but which are necessary for effective collaboration (Leatt et al, 2002: 4-6). The MOU indicates, directs, prescribes, defines and restricts by virtue of agreement on policy, operational and contractual issues pertaining to the collaboration. After it was signed by all member institutions, indicating their acceptance of the content of the MOU, it became the basis and guide for the regional undergraduate nursing platform and collaboration (CHEC, 2006:10).

The MOU, as a guiding document, stipulates the composition, terms of reference, reporting lines and meeting procedures of committees established for the governance and management of the regional undergraduate nursing platform. The CHEC Board of Directors Committee has representation from the Deputy Vice Chancellors of the participating institutions. The Nursing Academic Board (NAB) is represented by the Deans of Health Science Faculties, the Heads of Nursing Schools or Departments of the participating institutions as well as representation from the PGWC and is responsible for the governance of the platform. The NAB reports to the CHEC Board of Directors. The composition of the Nursing Management Committee includes the Heads of Nursing Schools, Programme Coordinators and a representative from the PGWC and is tasked with the management of the common teaching platform at operational level. The Nursing Management Committee reports to the Nursing Academic Board. The MOU further provides implementation guidelines regarding for example, student admissions and registration, programme and curriculum design and delivery including assessment and quality assurance processes (CHEC, 2006:17-41).

The first cohort of approximately 296 nursing students commenced their studies on the common teaching platform in 2005. As planned, the first year level of the four year programme was managed exclusively by the UWC. The Universities of Stellenbosch and Cape Town participated at differing degrees on the Common Teaching Platform from the second to fourth year of study. The University of Stellenbosch continued to manage the students registered in the second to fourth year levels of their BA Nursing programme. The students who were not successful in the first year at the University of Stellenbosch in 2004 were transferred to the UWC at the beginning of 2005, since Stellenbosch University did not have a student intake as of 2005. In this fashion, the Stellenbosch BA Nursing programme was phased out by the end of 2007. The UCT was not offering an undergraduate nursing degree prior to the decision that the three universities would combine their efforts and skills to train nurses for the Western Cape region.

Collaboration on the common teaching platform has however not been without challenges. The effectiveness of this regional collaboration is currently being evaluated. Despite the challenges a total of $220(74.3 \%)$ students proudly took the pledge of service and graduated in March 2009 in the company of guests and academics of the three universities who contributed to their education since 2005 . They were the first cohort of nursing students who graduated as products of the common teaching platform.

\section{Summary}

It was imperative that the education system in South Africa be transformed, resized and reshaped, to redress past inequities, be applicable to the new social order post apartheid and to respond to the financial state within the education sector and the country as a whole. The thread through the general history of the education system in South Africa, higher education in general and nursing education in particular, illustrates that change in the education system was unavoidable. The challenge however is to evaluate the expanse and degree to which true transformation has actually taken place.

Literature expounds on the fact that the nature of collaboration differs internationally compared to the national context. No international examples of collaboration were found in literature where students register at only one university for the entire programme, and where partner institutions participate in the delivery of the programme at each year level of the degree as is evident in the Western Cape common teaching platform for undergraduate nurse education. An extensive literature search showed that collaboration in nursing programmes in South Africa is not a common phenomenon. Despite the significance of the planned changes more than a decade ago, there is little discussion and evidence of empirical research within nursing literature regarding the way in which these changes have occurred or documentation of the experiences of those involved.

The gap in literature pertaining to the national and local experiences of collaborations and mergers in higher education in general and nursing education in particular reinforces the need for evaluations to be conducted and documented to strengthen the existing body of literature.

\section{Conclusion}

Through this article, the author has attempted to describe the context of the policy changes in the higher education system and how the Western Cape responded to the decisions affecting nursing education in the region. It is clear that although the Minister of Education announced that one institution would be the enrolling institution for undergraduate nursing in the Western Cape, the CHEC proposal of a common teaching platform was viewed as a variant of the Minister's decision and was adopted as the Western Cape's response to transformation and restructuring of nursing education for the region.

The author also clarified the concepts of collaboration and mergers in higher education and shared some international and national experiences of collaboration and mergers. This article is the first of a series of articles planned for publication based on the author's PhD study which evaluates the effectiveness of the regional collaboration for the common teaching platform for undergraduate nurses in the Western Cape.

\section{References}

BROWN, NE 2004: The Shift from Apartheid to Democracy: Issues and Impacts on Public Libraries in Cape Town, South A frica. LIBRI-COPENHAGEN. 54(3): 169-178.

CAPE HIGHER EDUCATION CON- 
SORTIUM (CHEC) 2006: (Unpublished). Integrated Planning framework and Memorandum of understanding: $\mathrm{A}$ common teaching Platform for Undergraduate Nursing in the Western Cape.

COUNCILONHIGHEREDUCATION 1999/2000: CHE Annual Report. Pretoria.

DEPARTMENT OF EDUCATION, 1997: Education White Paper 3: A Programme for the Transformation of Higher Education. General Notice No 1196 of 1997. Pretoria, Government Printers.

DEPARTMENT OF EDUCATION, 2001: National Plan for Higher Education. Pretoria, Government Printers.

DEPARTMENT OF EDUCATION, 2002: Transformation and Restructuring: A New Institutional landscape for Higher Education. Government Gazette No.23549, 21 June 2002. Pretoria, Government Printers.

HAY,HR; FOURIE,M \& HAY,JF 2001: Are institutional combinations, mergers or amalgamations the answer? An investigation into staff perceptions. Sibinet, 15(1): $100-108$.

JANSEN, J 2003: Mergers in South African higher education: theorising change in transitional contexts. Politikon: South African Journal of Political Studies. 30(1): 27-51.

LEATT, J \& PRETORIUS, T 2004: Regional Collaboration and the transformation of Higher Education in South Africa. A paper prepared for the European Higher Education Society (EAIR) Conference on "Knowledge Society Crossroads". Barcelona. http:// www.chec.ac.za/introduction/ Barcelona.pdf

LEATT,J; REZELMAN, M; BLYTH, W \& SYMES, A 2002: Discussion Paper prepared for the Cape Higher Education Consortium (CHEC): A Practical Approach to Systemic Collaboration in the Western Cape Higher Education.

LUND, CH; TATE, ET \& HYDEROBERTSON, B 1998: Benefits and Challenges of a Graduate Nursing Consortium. Nurse Educator, 23(6): 13-16.
MFUSI, MX 2004: The effects of higher education mergers on the resultant curricular of the combined institutions. South African Journal of Higher Education. 18(1): 98-110.

MOLZAHN,AE \& PURKIS, ME 2004: Collaborative Nursing Education Programs: Challenges and Issues. Nursing Leadership. 17(4): 41-55.

NATIONAL COMMISSION ON HIGHER EDUCATION(NCHE) 1996: A framework for transformation: Final Report. Pretoria, Government Printers.

OREGON CONSORTIUM FOR NURSING EDUCATION (OCNE), 2007: An Innovative nursing education network to promote high quality, compassionate health care. http:// www.ocne.org/media/ update on progress.pdf . 